\title{
Direct Peroral Cholangioscopy in the Management of Difficult Biliary Stones: a New Tool to Confirm Common Bile Duct Clearance. Results of a Preliminary Study
}

\author{
Andrea Anderloni ${ }^{1}$, Francesco Auriemma ${ }^{1}$, Alessandro Fugazza ${ }^{1}$, Edoardo Troncone $^{2}$, Luis Maia ${ }^{3}$, Roberta Maselli ${ }^{1}$, \\ Silvia Carrara ${ }^{1}$, Ferdinando D’Amico ${ }^{1}$, Paul J. Belletrutti ${ }^{4}$, Alessandro Repici ${ }^{4}$
}

1) Digestive Endoscopy Unit,

Division of Gastroenterology, Humanitas Research Hospital, Milan, Italy

2) Department of Systems Medicine, University of Rome Tor Vergata, Rome, Italy

3) Gastroenterology

Department, Porto University Hospital Center, Porto, Portugal

4) Humanitas University, Rozzano, Milan, Italy

\begin{abstract}
Background \& Aims: Endoscopic sphincterotomy (ES) with stone extraction is the standard treatment for choledocholithiasis. After stone retrieval, balloon-occluded cholangiography is generally performed to confirm bile duct clearance but can miss residual stones particularly in patients with residual small-sized stones, a large bile duct or pneumobilia. In addition, difficult common bile duct (CBD) stones requiring advanced endoscopic techniques for retrieval are a potential risk factor for choledocholithiasis recurrence.

Methods: We performed a retrospective evaluation of a prospectively maintained procedures database. From July 2016 to December 2017, all patients with difficult CBD stones who underwent endoscopic retrograde cholangiopancreatography (ERCP) with papillary balloon dilation-assisted stone retrieval and subsequent direct per-oral cholangioscopy (DPOC) using standard gastroscopes to confirm CBD clearance were analyzed. Results: Thirty-six patients who underwent ERCP and DPOC were included. Technical success, defined as deep intubation of CBD with hepatic hilum visualization, was achieved in 31 of 36 patients (86\%). During DPOC, residual CBD stones were visualized and removed in 7 of 31 patients (22.5\%). After a mean of 241 \pm 56 days of follow-up post-DPOC, no serious adverse events were reported, and there was no evidence or suspicion of recurrent choledocholithiasis.

Conclusions: Direct per-oral cholangioscopy immediately following difficult CBD stone removal was safe, feasible and accurate. In this setting, DPOC at the time of ERCP appears to be a very useful tool to achieve complete clearance of choledocholithiasis.
\end{abstract}

Key words: cholangioscopy - ERCP - difficult biliary stones - DPOC.

Abbreviations: CBD: common bile duct; DASE: dilation-assisted stone extraction; DPOC: direct per-oral cholangioscopy; EML: endoscopic mechanical lithotripsy; EPLBD: endoscopic papillary large-balloon dilation; ERCP: endoscopic retrograde cholangiopancreatography; ES: endoscopic sphincterotomy; IDUS: intraductal ultrasound.

\section{INTRODUCTION}

Endoscopic sphincterotomy (ES) with stone extraction is the recommended standard treatment for symptomatic choledocholithiasis [1]. However, in 10 to $15 \%$ of cases, common bile duct (CBD) stones are difficult to extract by standard endoscopic techniques and more advanced procedures to achieve complete stone clearance might be required [2-4].

Endoscopic papillary largeballoon dilation (EPLBD) with or without ES has been widely considered as an effective and safe alternative technique along with endoscopic mechanical lithotripsy (EML) for the removal of difficult bile duct stones [5, 6]. A recent randomized multicenter study demonstrated that EPLBD was significantly superior to ES for retrieval of CBD stones $\geq 13 \mathrm{~mm}$ in diameter, reducing the need for mechanical lithotripsy [7].

Furthermore, difficult bile duct stones are considered a risk factor for choledocholithiasis recurrence, recognized as a late adverse event after endoscopic retrograde cholangiopancreatography (ERCP) [8-10]. As a result, acute conditions such as cholangitis and biliary pancreatitis may occur and require repeated ERCP examination carrying the further risk of iatrogenic adverse events [11-14].

After stone retrieval, balloon-occluded cholangiography is generally performed to confirm bile duct clearance [15]. 
However, in patients with residual small-sized stones, a large bile duct or pneumobilia, adequate bile duct evaluation may be challenging. Even if the stone extraction appears to be complete on the cholangiogram, residual stones may still remain in the $\mathrm{CBD}$, potentially leading to further long-term symptoms and healthcare resource utilization [16]. Tsuchiya et al. [17] reported a $23.7 \%$ rate of residual CBD stones detected by intraductal ultrasound (IDUS) but not seen on cholangiography. However, the role of IDUS is limited due to probe availability, probe fragility and high procedure costs.

In recent years, there has been an increasing development of through-the-scope cholangioscopy techniques especially in the field of large stone management. These instruments are principally dedicated to the treatment of difficult biliary stones with laser or electrohydraulic lithotripsy, although other indications such as the confirmation of bile duct clearance at the end of the procedure have been also proposed [18]. Nevertheless, due to the high costs, these cholangioscopic procedures are usually performed only in specific scenarios, not solely for bile duct clearance confirmation. Direct peroral cholangioscopy (DPOC) refers to the use of standard upper endoscopes for the direct visualization of the biliary tract, usually after large ES or EPLBD [19, 20].

In this study, we aimed to evaluate the feasibility and safety of DPOC to confirm complete CBD clearance after dilationassisted CBD stone extraction.

\section{METHODS}

This was a retrospective evaluation of a prospectively maintained endoscopic procedure database. From July 2016 to December 2017, all patients with suggestive features of difficult biliary stones (both CBD dilated more than $12 \mathrm{~mm}$ and stone diameter larger than $10 \mathrm{~mm}$ ) who underwent ERCP with dilation-assisted stone extraction (DASE) followed by DPOC were considered eligible for the study. Patients who were under the age of 18, pregnant, or critically ill with a pre-operative ASA IV score, as well as patients with concomitant cholecystitis or undergoing double anti-thrombotic therapy were excluded from the analysis. After confirmation of complete stones retrieval by a negative occlusive cholangiogram, a DPOC was performed using a standard forward-viewing gastroscope. The exact choice of gastroscope was at the discretion of the endoscopist.

\section{Endoscopic retrograde cholangiopancreatography}

All ERCPs were performed using a duodenoscope (JF 160V, Olympus, Tokyo, Japan; or ED-530XT, Fujifilm, Japan) under $\mathrm{CO} 2$ insufflation. Deep sedation was conducted by anesthetistadministered propofol-based sedation, with patients generally lying in left-lateral position. If performed, ES was achieved using a standard pull-type sphincterotome (Autotome or Ultratome; Boston Scientific Co. United States). Endoscopic papillary large-balloon dilation was carried out using a controlled radial expansion balloon (CRE, Boston Scientific Corp., Marlborough, United States). A contrast medium at a 1:1 dilution was generally used for cholangiography (Fig. 1). The equipment used to extract the CBD stones included a retrieval balloon catheter, a Dormia basket catheter, or a combination of

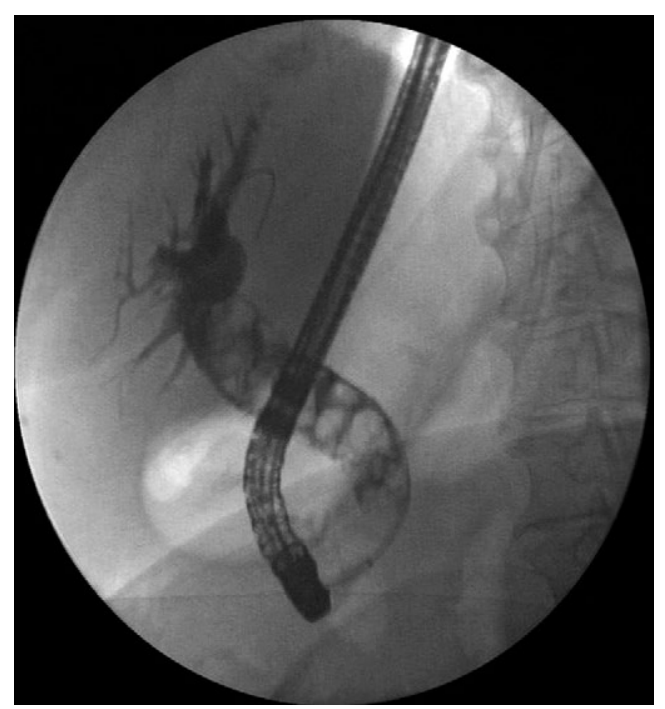

Fig. 1. Cholangiography: dilated common bile duct up to $20 \mathrm{~mm}$ and multiple (>10) stones.

both. Mechanical lithotripsy was additionally performed when stone extraction proved to be increasingly difficult as a result of a large-sized CBD or in the case of disproportion between the stone diameter and bile duct caliber below. After stone extraction, balloon-occluded cholangiography was performed to check for complete clearance of the CBD stones. If any residual stones were observed, repeated endoscopic treatments were performed until the balloon-occluded cholangiogram was negative.

\section{Direct per-oral cholangioscopy}

All of the DPOC procedures were carried out immediately after a negative balloon-occluded cholangiography during the same endoscopic session. Ultraslim $(5.9 \mathrm{~mm}$ diameter, $2.0 \mathrm{~mm}$ working channel) or slim (8.5 mm diameter, $2.8 \mathrm{~mm}$ working channel) endoscopes (FujiFilm EG 530NW or EG 530FP), or standard gastroscopes (9.9 mm diameter, $2.8 \mathrm{~mm}$ working channel) (Olympus GIF-HQ190) were inserted via the per-oral route to directly access the bile duct, also under $\mathrm{CO} 2$ insufflation.

Briefly, the endoscope was advanced through the mouth down to the second part of the duodenum. Then, at the endoscopist's discretion, the scope was turned into the orifice of the major papilla either directly or by means of a guidewire (Jagwire 0.035 inch-450 cm, Boston Scientific Co., United States) positioned deeply into the intrahepatic biliary tree. Then, the endoscope was further advanced into the bile duct as far as possible (Fig. 2, 3, 4). Neither balloon catheters, nor overtubes or other devices were used for this purpose. Technical success was defined as deep intubation of the CBD with hepatic hilum visualization. The DPOC time was defined as the interval between the endoscope inserting into the mouth of the patient up to the end of the procedure.

\section{RESULTS}

\section{Patients}

Thirty-six patients with difficult CBD stones undergoing both DASE and DPOC were included in this study (Table I). 


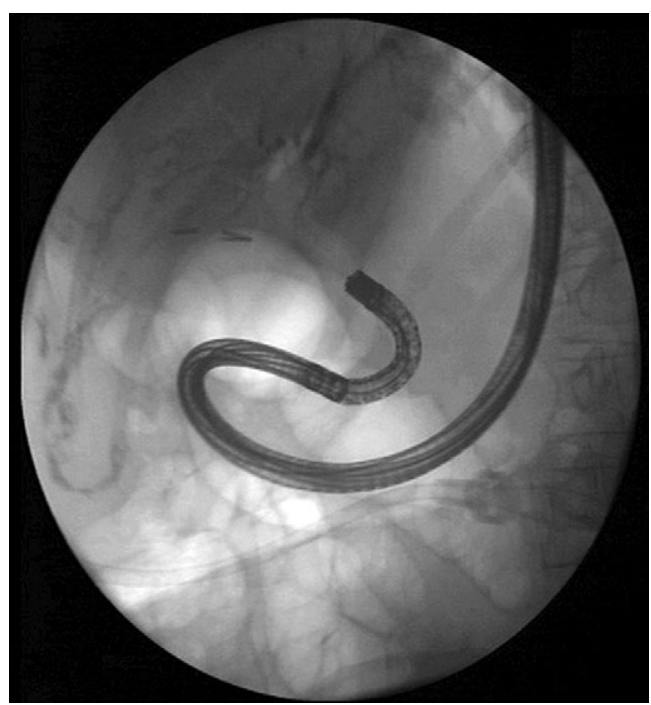

Fig. 2. Fluoroscopic appearance of direct peroral cholangioscopy with the tip of endoscope inside the common bile duct (air cholangiography).

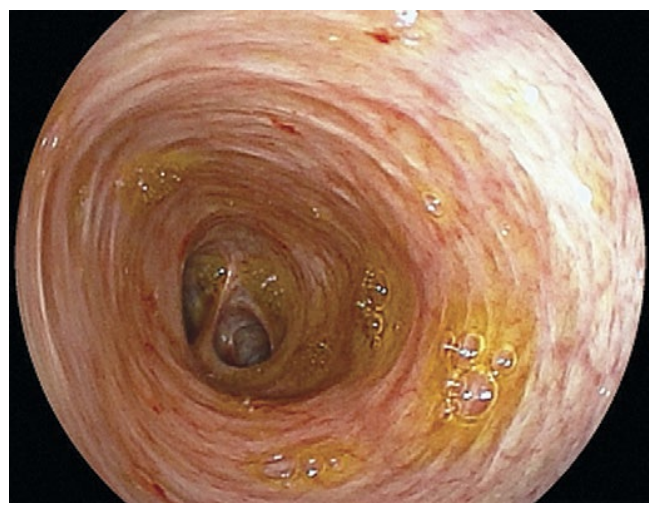

Fig. 3. Hepatic hilum visualization under direct peroral cholangioscopy.

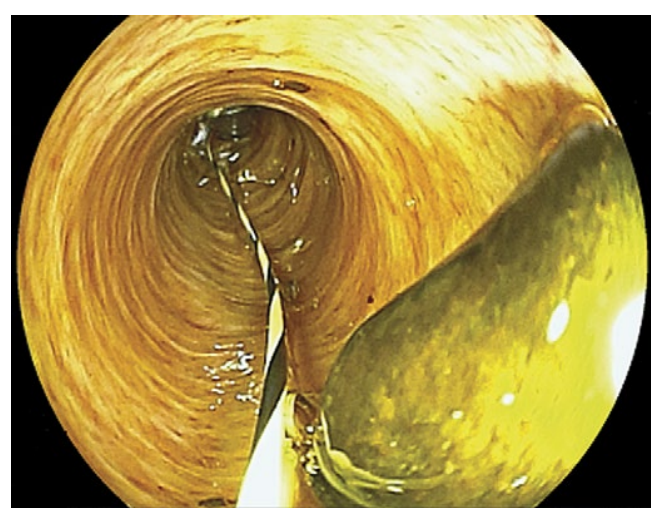

Fig. 4. Stone fragment visualization in the distal common bile duct under direct peroral cholangioscopy.

The mean patient age was $72.4 \pm 11.6$ years (range, $42-89$ years) and $20(55 \%)$ of the patients were female. Thirteen patients (36\%) had a previous cholecystectomy. Twenty patients (55\%) had an intact papilla (i.e. patients naïve to ERCP and ES), of whom two had a medical history of a subtotal gastrectomy with Billroth-II anastomosis and one had a peri-diverticular position of the papilla. Of the remaining 16 patients, 10 had already undergone previous ERCPs and ES with or without attempted stone extraction, whilst the remaining 6 studied subjects had experienced an ERCP with failed cannulation in another center and, as such, were then referred to our institute.

Table I. Patient characteristics

\begin{tabular}{ll}
\hline Patients & $\mathrm{n}=36$ \\
Age (years) & $72.4 \pm 11.6$ (range 42-89) \\
Gender, female n (\%) & $20(55 \%)$ \\
ASA score & 6 patients ASA 1 \\
& 19 patients ASA 2 \\
& 11 patients ASA 3 \\
Intact papilla (patients naïve to ERCP) & 20 patients \\
$\quad$ Peri-diverticular papilla & \multicolumn{1}{c}{1 patient } \\
$\quad$ Billroth-II gastrectomy & 10 patients \\
Recurrent CBD stones & 6 patients \\
Failed ERCP (referred from other center) &
\end{tabular}

CBD: common bile duct; ERCP: endoscopic retrograde cholangiopancreatography.

\section{ERCP and DPOC}

The results of the ERCP examinations are listed in Table II. Stone extraction was carried out by means of retrieval balloon catheter, Dormia basket catheter, or a combination of both. Mechanical lithotripsy was also performed in two cases. Mean procedural time (ERCP including DPOC) was $51 \pm 14$ minutes.

\section{Table II. Results of ERCP}

\begin{tabular}{ll}
\hline $\begin{array}{l}\text { Number of CBD stones } \\
1-2 \text { stones }\end{array}$ & 15 patients \\
$3-5$ stones & 15 patients \\
more than 5 stones & 6 patients \\
Maximum stone diameter & $12.9 \pm 3.4 \mathrm{~mm}$ (range $10-20 \mathrm{~mm}$ ) \\
(mean \pm SD) & $15.8 \pm 3.7 \mathrm{~mm}$ (range $12-30 \mathrm{~mm}$ ) \\
$\begin{array}{l}\text { Maximum CBD diameter CBD } \\
\text { (mean } \pm \text { SD) }\end{array}$ & \\
ES and/or EPLBD & 30 patients \\
$\quad$ ES + EPLBD & 6 patients \\
EPLBD alone & $13.4 \pm 2.1 \mathrm{~mm}$ (range 10-18 mm) \\
$\begin{array}{l}\text { Maximum balloon dilation } \\
\text { (mean } \pm \text { SD) }\end{array}$
\end{tabular}

CBD: common bile duct; ES:endoscopic sphincterotomy; EPLBD: endoscopic papillary large-balloon dilation

The DPOC results are shown in Table III. Technical success was achieved in 31 of 36 patients (86\%). Guide-wire assisted intubation of CBD was performed in 20 cases (55\%), while in the remaining 16 cases direct free-hand intubation was utilized. The slim endoscope was used in 15 patients, the ultra-slim endoscope was used in 12 patients and a standard gastroscope in the remaining 9 patients.

During DPOC, residual CBD stones were found in 7 of 31 patients $(22.5 \%)$ in whom the hepatic bifurcation was reached. Mean residual stone diameter was $6 \pm 1 \mathrm{~mm}$. In 4 patients, the residual stones were successfully extracted during per-oral cholangioscopy under direct endoscopic visualization using a 
Table III. Results of direct per-oral cholangioscopy (DPOC)

\begin{tabular}{ll}
\hline Procedure time (mean \pm SD) & $\begin{array}{l}6.3 \pm 2.5 \mathrm{~min} \\
(\text { range, } 3-15 \mathrm{~min})\end{array}$ \\
$\begin{array}{l}\text { Guide-wire assisted intubation of CBD } \\
\text { Site reached }\end{array}$ & \\
Hilum or intrahepatic ducts & 31 patients $(86 \%)$ \\
Distal CBD and not visualized hilum & 3 patients $(8 \%)$ \\
Failed CBD intubation & 2 patients $(6 \%)$ \\
Residual stones identified & 7 patients $(22.5 \%)$ \\
Mean residual stone diameter & $6 \pm 1$ mm \\
Residual stone(s) treatment & \\
DPOC & 4 cases \\
Dormia basket & 3 cases \\
Retrieval Roth-Net & 1 case \\
Standard ERCP techniques & 3 cases \\
\hline
\end{tabular}

CBD: common bile duct; DPOC: direct per-oral cholangioscopy.

basket catheter (in 3 cases) or a retrieval device (Roth-Net ${ }^{\oplus}$, US Endoscopy) (in 1 case). In the remaining 3 patients, residual stones were removed by using a duodenoscope and standard ERCP devices after the cholangioscopy.

Mean DPOC procedure time was 6.3 $\pm 2.5 \mathrm{~min}$ (range 3-15 min). No serious procedure-related adverse events (such as bleeding, pancreatitis, biliary tract infection or perforation) occurred.

Patients were followed up for a mean $241 \pm 56$ days after the ERCP plus DPOC. At 3- and 6-months post-procedure, all subjects underwent outpatient biochemistry and abdominal ultrasound evaluation as well as a phone-call interview. During this follow-up, there were no patients with either evidence or suspicion of recurrent CBD stones.

\section{DISCUSSION}

Endoscopic retrograde cholangiopancreatography has been widely accepted as an effective and minimally invasive treatment for CBD stones. Nevertheless, in clinical practice, acute cholangitis and pancreatitis due to recurrent choledocholithiasis occur frequently. Symptomatic recurrent CBD stones can occur in 4 to $24 \%$ of cases after successful endoscopic stone retrieval. Particularly in the case of multiple or large CBD stones, small stone fragments which are not detectable on the final cholangiogram can remain even after apparently complete endoscopic stone removal [21].

Hence, fluoroscopic confirmation of complete bile duct clearance after endoscopic treatment may be misleading. The most widely used technique is occlusion-balloon cholangiography, although different studies have reported that it is an imperfect tool in comparison with other modalities proposed to deal with this issue (i.e. mother-baby system cholangioscopy or IDUS) $[16,17]$.

In recent years, there has been increased development of cholangioscopy techniques, devices and applications. Huang et al. [19] reported $22.7 \%$ of patients having residual CBD stones revealed at DPOC performed by means of an ultra-slim scope, with an average stone diameter of 3-4 $\mathrm{mm}$.

In this study, we reported the first retrospective analysis of DPOC performed by means of not only ultra-slim, but also slim and standard gastroscopes, in order to further evaluate clearance of the lower biliary tract after ERCP for difficult stones. Our results showed a high CBD intubation rate of $94 \%$ (34 of 36 patients), with a technical success rate, defined as direct endoscopic hepatic hilum visualization, of $86 \%$ (31 of 36 patients).

In terms of the rate of unidentified residual stones, our results mirror those of previous studies [16, 17, 19]. Our rate of undetected residual CBD stones at occlusion-balloon cholangiography was $22.5 \%$, with most residual stones/ fragments being of small size, not exceeding $7 \mathrm{~mm}$ in diameter. It is unclear whether these small residual stones are of clinical significance; however, it is conceivable that these residual stones might not be excreted after the procedure and may be a nidus for stone recurrence and/or cause other long-term complications [22].

Meves et al. [23] firstly reported a large series of 100 patients in whom trans-nasal cholangioscopy was used for different diagnostic and therapeutic purposes (evaluation of indeterminate biliary strictures, confirmation of CBD stone clearance, tumor tissue ablation, etc.) using an ultraslim gastroscope; the technical success rate was nearly $81 \%$. Nevertheless, this study also clearly showed an important drawback of the technique: that access to the CBD is often limited and the evaluation of the intrahepatic ducts is feasible only in a minority of patients. In a recent study, Lenze et al. [24] reported the first clinical experience of DPOC with a new anchoring technique using the guide probe of Kautz. Biliary access and visualization of the target region were achieved in $18 / 20$ procedures (90\%). This and subsequent studies often reported the feasibility of direct cholangioscopy only by means of balloon-anchoring technique, overtube-assisted intubation of CBD, or dedicated double-bending tip endoscopes [25-28].

Direct per-oral cholangioscopy does not require anchoring or a dedicated cholangioscope, allowing cholangioscopy to be performed without additional costs or resources. In our study, we showed the safety and efficacy of this method performed with commonly available gastroscopes after EPLBD. Most importantly, we used a free-hand technique, without the need of specifically designed accessories to achieve CBD intubation.

Direct per-oral cholangioscopy performed with commonly available gastroscopes (ultra-slim, slim or standard endoscopes) has several advantages over the mother-baby endoscopic system. It indeed provides all the functionality of standard endoscopes enabling the extraction of residual CBD stones during the same endoscopic procedure under direct visualization. A basket catheter can pass through the $2-\mathrm{mm}$ working channel of the ultra-slim endoscope to grasp residual stones. Also, a Roth-Net basket retrieval device can be used in the case of an extremely dilated CBD, through a standard 2.8 $\mathrm{mm}$ working channel of slim or standard endoscopes. Secondly, it displays superior imaging quality.

Another encouraging aspect of DPOC is its short procedural time. In our cohort, the mean employed time was $6.3 \pm 2.5 \mathrm{~min}$ (range $3-15 \mathrm{~min}$ ), including the supplementary extraction procedures performed under direct endoscopic view. Considering that the overall mean procedural time was $51 \pm 14$ minutes, additional DPOC examination increased it by only $10 \%$. In our opinion, this is an acceptable additional time in the context of complex ERCP procedures in order to 
better evaluate CBD clearance. Therefore, by directly checking and confirming the complete clearance of the $\mathrm{CBD}$ at the end of the ERCP, DPOC could allow significant total cost savings for both the procedure itself and potential avoidance of any future procedures or healthcare utilization due to retained $\mathrm{CBD}$ stones. However, we have to bear in mind that this technique should be considered as an advanced therapeutic biliopancreatic procedure. As in all other advanced procedures, it requires expertise and an adequate background.

In our series, no serious adverse events (such as bleeding, pancreatitis, biliary tract infection, or perforation) occurred either during the procedures or follow-up period. In addition, air embolism, a well-defined adverse event of cholangioscopy, was not observed [29].

Limitations of this study concern first of all its retrospective and non-randomized type alongside the relatively small number of patients enrolled. Therefore, it is reasonable to consider these results as a preliminary study. In addition to this, we arbitrarily considered DPOC as a procedure capable of ensuring $100 \%$ the presence or absence of stone residual, compared to the less performing gold-standard, such as the occlusion balloon cholangiogram. Finally, longer follow-up may also be required to ascertain that no patient in the DPOC group had recurrence of the stones.

\section{CONCLUSION}

In the setting of difficult CBD stones, conventional ERCP with balloon-occluded cholangiography may not be the most reliable or satisfactory method for confirming complete bile duct clearance. Alternatively, DPOC using a standard endoscope appears to be a very useful and economical tool to not only, more confidently confirm the clearance of CBD stones, but also to immediately extract any identified residual stones/fragments. Our procedure data and relatively long recurrence-free follow-up period suggests that DPOC is feasible, efficient, accurate and safe in this subgroup of patients with difficult CBD stones. Further randomized-controlled studies addressing specific primary and secondary outcomes are eagerly warranted.

\section{Conflicts of interest: None to declare}

Authors' contributions: A.A. and A.R. conceived the study. A.A. performed the endoscopic examinations. F.A. and A.F. drafted the manuscript. E.T., L.M, R.M., S.C. F.D'A. followed up the patients. P.J.B checked English language. A.R. critically revised the manuscript. All authors approved the final version of the manuscript before submission.

\section{REFERENCES}

1. European Association for the Study of the Liver (EASL). EASL Clinical Practice Guidelines on the prevention, diagnosis and treatment of gallstones. J Hepatol 2016;65:146-181. doi:10.1016/j.jhep.2016.03.005

2. Garg PK, Tandon RK, Ahuja V, Makharia GK, Batra Y. Predictors of unsuccessful mechanical lithotripsy and endoscopic clearance of large bile duct stones. Gastrointest Endosc 2004;59:601-605. doi:10.1016/ S0016-5107(04)00295-0
3. Cipolletta L, Costamagna G, Bianco MA, et al. Endoscopic mechanical lithotripsy of difficult common bile duct stones. Br J Surg 1997;84:14071409. doi:10.1111/j.1365-2168.1997.02831.x

4. Chang WH, Chu CH, Wang TE, Chen MJ, Lin CC. Outcome of simple use of mechanical lithotripsy of difficult common bile duct stones. World J Gastroenterol 2005;11:593-596. doi:10.3748/wjg. v11.i4.593

5. Kim TH, Kim JH, Seo DW, et al. International consensus guidelines for endoscopic papillary large-balloon dilation. Gastrointest Endosc 2016;83:37-47. doi:10.1016/j.gie.2015.06.016

6. Park JS, Jeong S, Lee DK, et al. Comparison of endoscopic papillary large balloon dilation with or without endoscopic sphincterotomy for the treatment of large bile duct stones. Endoscopy 2019;51:125-132. doi:10.1055/a-0639-5147

7. Karsenti D, Coron E, Vanbiervliet G, et al. Complete endoscopic sphincterotomy with vs. without large-balloon dilation for the removal of large bile duct stones: randomized multicenter study. Endoscopy 2017;49:968-976. doi:10.1055/s-0043-114411

8. Sugiyama M, Suzuki Y, Abe N, Masaki T, Mori T, Atomi Y. Endoscopic retreatment of recurrent choledocholithiasis after sphincterotomy. Gut 2004;53:1856-1859. doi:10.1136/gut.2004.041020

9. Konstantakis C, Triantos C, Theopistos V, et al. Recurrence of choledocholithiasis following endoscopic bile duct clearance: Long term results and factors associated with recurrent bile duct stones. World J Gastrointest Endosc 2017;9:26-33. doi:10.4253/wjge.v9.i1.26

10. Kato S, Chinen K, Shinoura S, Kikuchi K. Predictors of bile duct stone recurrence after endoscopic extraction for naïve major duodenal papilla: A cohor study. PLoS One 2017;12:e0180536. doi:10.1371/journal. pone.0180536

11. Tanaka M, Takahata S, Konomi H, et al. Long-term consequence of endoscopic sphincterotomy for bile duct stones. Gastrointest Endosc 1998;48:465-469. doi:10.1016/S0016-5107(98)70086-0

12. Sugiyama M, Atomi Y. Risk factors predictive of late complications after endoscopic sphincterotomy for bile duct stones: long-term (more than 10 years) follow-up study. Am J Gastroenterol 2002;97:2763-2767. doi:10.1111/j.1572-0241.2002.07019.x

13. Prat F, Malak NA, Pelletier G, et al. Biliary symptoms and complications more than 8 years after endoscopic sphincterotomy for choledocholithiasis. Gastroenterology 1996;110:894-899. doi:10.1053/ gast.1996.v110.pm8608900

14. Paspatis GA, Paraskeva K, Vardas E, et al. Long-term recurrence of bile duct stones after endoscopic papillary large balloon dilation with sphincterotomy: 4-year extended follow-up of a randomized trial. Surg Endosc 2017;31:650-655. doi:10.1007/s00464-016-5012-9

15. Prat F, Amouyal G, Amouyal P, et al. Prospective controlled study of endoscopic ultrasonography and endoscopic retrograde cholangiography in patients with suspected common-bileduct lithiasis. Lancet 1996;347:75-79.

16. Itoi T, Sofuni A, Itokawa F, Shinohara Y, Moriyasu F, Tsuchida A. Evaluation of residual bile duct stones by peroralcholangioscopy in comparison with balloon-cholangiography. Dig Endosc 2010;22 Suppl 1:S85-S89. doi:10.1111/j.1443-1661.2010.00954.x

17. Tsuchiya S, Tsuyuguchi $T$, Sakai $Y$, et al. Clinical utility of intraductal US to decrease early recurrence rate of common bile duct stones after endoscopic papillotomy. J Gastroenterol Hepatol 2008;23:1590-1595. doi:10.1111/j.1440-1746.2008.05458.x

18. Ghersi S, Fuccio L, Bassi M, Fabbri C, Cennamo V. Current status of peroralcholangioscopy in biliary tract diseases. World J Gastrointest Endosc 2015;7:510-517. doi:10.4253/wjge.v7.i5.510 
19. Huang SW, Lin CH, Lee MS, Tsou YK, Sung KF. Residual common bile duct stones on direct peroralcholangioscopy using ultraslim endoscope. World J Gastroenterol 2013;19:4966-4972. doi:10.3748/ wjg.v19.i30.4966

20. Tringali A, Lemmers A, Meves V, et al. Intraductal biliopancreatic imaging: European Society of Gastrointestinal Endoscopy (ESGE) technology review. Endoscopy 2015;47:739-753. doi:10.1055/s-0034-1392584

21. Cheon YK, Lehman GA. Identification of risk factors for stone recurrence after endoscopic treatment of bile duct stones. Eur J Gastroenterol Hepatol 2006;18:461-464.

22. Siddique I, Mohan K, Khajah A, et al. Sphincterotomy in patients with gallstones, elevated LFTs and a normal CBD on ERCP. Hepatogastroenterology 2003;50:1242-1245.

23. Meves V, Ell C, Pohl J. Efficacy and safety of direct transnasal cholangioscopy with standard ultraslim endoscopes: results of a large cohort study. Gastrointest Endosc 2014;79:88-94. doi:10.1016/j. gie.2013.05.032

24. Lenze F, Nowacki TM, Beyna T, Ullerich H. Direct peroral cholangioscopy with a new anchoring technique using the guide probe of Kautz - first clinical experiences. Endoscopy 2017;49:909-912. doi:10.1055/s-0043-109864

25. Pohl J, Ell C. Direct transnasal cholangioscopy with ultraslimendoscopes: a one-step intraductal balloon-guided approach. Gastrointest Endosc 2011;74:309-316. doi:10.1016/j.gie.2011.02.022

26. Albert JG, Friedrich-Rust M, Elhendawy M, Trojan J, Zeuzem S, Sarrazin C. Peroral cholangioscopy for diagnosis and therapy of biliary tract disease using an ultra-slim gastroscope. Endoscopy 2011;43:1004-1009. doi:10.1055/s-0030-1256623

27. Larghi A, Waxman I. Endoscopic direct cholangioscopy by using an ultra-slim upper endoscope: a feasibility study. Gastrointest Endosc 2006;63:853-857. doi:10.1016/j.gie.2005.07.050

28. Choi HJ, Moon JH, Ko BM, et al. Overtube-balloon-assisted direct peroralcholangioscopy by using an ultra-slim upper endoscope (with videos). Gastrointest Endosc 2009;69:935-940. doi:10.1016/j. gie.2008.08.043

29. Efthymiou M, Raftopolous S, Antonio Chirinos J, May GR. Air embolism complicated by the left hemiparesis after direct cholangioscopy with an intra-ductal balloon anchoring system. Gastrointest Endosc 2012;75:221-223. doi:10.1016/j.gie.2011.01.038 